STUDI

FRANCESI

\section{Studi Francesi}

Rivista quadrimestrale fondata da Franco Simone

172 (LVIII | I) | 2014

Varia

\title{
Aa. Vv., Le prince et l'écrivain, Alexandre Dumas et le prince Napoléon. Correspondances et textes inédits
}

\section{Lise Sabourin}

\section{(2) OpenEdition}

1 Journals

\section{Édition électronique}

URL : http://journals.openedition.org/studifrancesi/2207

DOI : 10.4000/studifrancesi.2207

ISSN : 2421-5856

Éditeur

Rosenberg \& Sellier

\section{Édition imprimée}

Date de publication : 1 avril 2014

Pagination : 164-165

ISSN : 0039-2944

\section{Référence électronique}

Lise Sabourin, «Aa. VV., Le prince et l'écrivain, Alexandre Dumas et le prince Napoléon. Correspondances et textes inédits », Studi Francesi [En ligne], 172 (LVIII | I) | 2014, mis en ligne le 01 avril 2014, consulté le 18 septembre 2020. URL : http://journals.openedition.org/studifrancesi/2207 ; DOI : https://doi.org/ 10.4000/studifrancesi.2207

Ce document a été généré automatiquement le 18 septembre 2020.

\section{(c)}

Studi Francesi è distribuita con Licenza Creative Commons Attribuzione - Non commerciale - Non opere derivate 4.0 Internazionale. 


\title{
Aa. Vv., Le prince et l'écrivain, Alexandre Dumas et le prince Napoléon. Correspondances et textes inédits
}

\author{
Lise Sabourin
}

\section{RÉFÉRENCE}

AA. VV. Le prince et l'écrivain, Alexandre Dumas et le prince Napoléon. Correspondances et textes inédits, «Cahiers Alexandre Dumas», n. 39, 2012, diffusion Paris, Encrages/Belles lettres, 2012 , pp. 255.

1 Alexandre Dumas le républicain a été, on le sait, l'ami de deux princes, le duc d'Orléans, gendre du roi Ferdinand IV sous lequel avait été emprisonné son père, et le prince Napoléon, dit «Plonplon», le libéral cousin de Napoléon III disgracié pour son action en faveur de Garibaldi.

Les «Cahiers Alexandre Dumas» 2012 rassemblent, au sein d'une trame de liaison écrite par Claude sсноре, les lettres de Dumas père et fils au prince Napoléon, celles de Dumas père au prince Galitzine, celle du prince Napoléon à Ida Dumas, des extraits de lettres du prince Napoléon et de Julius Gruzewski au prince Vladimir Galitizine, ainsi que des pièces relatives au duel du prince Napoléon et du comte de La Roche-Pouchin, des lettres de la comtesse son épouse, née Maria Czartoryska, transcrits par Claude scHoPP, Odile KRAKOVITCH et Anne-Marie CALLET-BLANCO, traduits pour les articles italiens issus de «L'Indipendente» par Chantal CHEMLAA. S'ajoute un résumé du Discours de S. A. I. Napoléon (sur la question italienne) prononcé au Sénat le $1^{\mathrm{er}}$ mars 1861 et de la Lettre sur l'histoire de France adressée au prince Napoléon par le duc d'Aumale en réponse.

3 L'amitié nouée avec le jeune prince exilé à Florence en 1840 est solide: Plonplon se charge d'apprendre à Dumas la mort accidentelle du duc d'Orléans en 1842; lui confie les démêlés complexes de son duel avec Pouchin en 1843; séjourne chez lui lors de sa visite à Paris en 1845 sous le nom de «comte de Monfort»; partage en 1861 son 
engagement contre la politique impériale inspirée par le Saint-Siège, avant de le retrouver à Naples peu après l'entrée triomphale de son beau-père, le roi VictorEmmanuel II, en 1862. La correspondance continue avec Dumas fils éprouvé par la mort de son père et le désastre français, quand le prince rouge devient conseiller général de la Corse en 1871, puis se retire à Prangins après la loi d'exil frappant en 1886 tous les membres des familles ayant régné en France.

Le répertoire biographique final (pp. 201-245) donne tous les renseignements utiles sur les personnes évoquées dans ces documents qui, ainsi réunis, ont non seulement l'avantage de fixer l'état des relations des Dumas avec ce prince célèbre, mais aussi fournissent des détails intéressants sur les relations franco-italiennes au milieu du XIX $\mathrm{X}^{\mathrm{e}}$ siècle. 